\title{
Corrigendum
}

\section{The Public Health Nutrition workforce and its future challenges: the US experience}

\author{
Betsy Haughton and Alexa George
}

First published online 5 August 2008

doi:10.1017/S1368980008001821. Published by Cambridge University Press 16 Apr 2008

The source for Tables 1 p 785, 2 p 786, 3 p 786 should read

From McCall and Keir ${ }^{(53)}$.

\section{Reference}

Betsy Haughton \& Alexa George (2008) The Public Health Nutrition workforce and its future challenges: the US experience. Public Health Nutr 11(8), 782-791. 